Int. J. Electrochem. Sci., 12 (2017) $8892-8907$

\title{
Effect of Dioctyl Sebacate on Corrosion Behavior of Fine-grain High-strength Reinforcement in Simulated Concrete Pore Solutions
}

\author{
Bilan Lin ${ }^{1,2, *}$ Zan Luo ${ }^{1}$, Chaonong Liu ${ }^{1}$, Xuefeng Liu ${ }^{1}$ and Yuye Xu ${ }^{3}$ \\ ${ }^{1}$ School of Material Science and Engineering, Xiamen University of Technology, Xiamen 361024, \\ China \\ ${ }^{2}$ Key Laboratory of Functional Materials and Applications of Fujian Province, Xiamen 361024, China \\ ${ }^{3}$ College of Civil Engineering, Huaqiao University, Xiamen, Fujian 361021, China \\ E-mail: $\underline{\text { linbilan@xmut.edu.cn }}$
}

doi: $10.20964 / 2017.10 .52$

Received: 1 July 2017 / Accepted: 12 August 2017 / Published: 12 September 2017

Dioctyl sebacate (DS) was used as a corrosion inhibitor for fine-grain high-strength reinforcement (HRBF500 reinforcement) in simulated concrete pore solutions (SCP solutions) with $3.5 \% \mathrm{NaCl}$. The corrosion behavior of HRBF500 reinforcement was investigated using potentiodynamic polarization curves, electrochemical impedance spectroscopy (EIS) diagrams, Mott-Schottky curves and scanning electron microscopy (SEM) observations. Comparisons were made with plain carbon steels (HPB300 reinforcement). In addition, the corrosion inhibition effect of the composite inhibitor, DS and molybdate, was studied. The results show that the cathodic corrosion process of HRBF500 is greatly inhibited by DS, which acts as a cathodic inhibitor. With an increase in DS content, the corrosion current density decreases and the electrochemical impedance increases; a reduction in donor concentration of the corrosion product membrane occurs. The corrosion of the HRBF500 reinforcement is substantially inhibited but not eliminates. A suitable DS concentration was approximately $2.0 \%$. Compared to HRBF500, for HPB300 reinforcement with $2 \%$ DS, the anodic polarization curve exhibits a passivation region, the impedance is considerably higher, and the corrosion almost disappears. The corrosion inhibition efficiency of DS is superior for HPB300 than that for HRBF500. Moreover, regarding the composite inhibitor of DS and molybdate, a synergistic inhibitive effect is well exerted. The corrosion protection efficiency for HRBF500 reinforcement is up to $99.3 \%$, and the corrosion current density is decreased to $0.08 \mu \mathrm{A} \cdot \mathrm{cm}^{-2}$, for more than two orders of magnitude.

Keywords: Reinforcement; Fine grain; Corrosion; Inhibitor; Simulated concrete pore solution; Dioctyl sebacate; Molybdate 


\section{FULL TEXT}

(C) 2017 The Authors. Published by ESG (www.electrochemsci.org). This article is an open access article distributed under the terms and conditions of the Creative Commons Attribution license (http://creativecommons.org/licenses/by/4.0/). 